ORIGINAL ARTICLE

\title{
Consensus and contention regarding redundant publications in clinical research: cross-sectional survey of editors and authors
}

\section{Yank, D Barnes}

See end of article for authors' affiliations .......................

Correspondence to: $\checkmark$ Yank, 5 Alma Street, apt 2, San Francisco, CA 94117, USA; vyank@itsa.ucsf.edu

Revised version received 6 May 2002

Accepted for publication 20 June 2002
Objectives: To examine the perspectives of journal editors and authors on overlapping and redundant publications in clinical research.

Design: Pretested cross-sectional survey, containing both forced choice and open ended questions, administered by mail to the senior editors $(\mathrm{N}=99)$ and one randomly selected author $(\mathrm{N}=99)$ from all journals in the Abridged Index Medicus (1996) that published clinical research.

Main measurements: The views of editors and authors about the extent of redundant publications, why they occur, how to prevent and respond to cases, and when the publication of overlapping manuscripts is justified.

Results: Seventy two per cent $(\mathrm{N}=71)$ of editors and $65 \%(\mathrm{~N}=64)$ of authors completed the survey. There was consensus between both groups that redundant publications occur because authors feel the pressure to publish and journals do not do enough to publicise, criticise, and punish cases, and that the publication of most types of overlapping articles is unacceptable. Sixty seven per cent of authors but only $31 \%$ of editors felt, however, that it was justified to publish an overlapping article in a nonpeer reviewed symposium supplement, and $68 \%$ of editors but $39 \%$ of authors supported imposing restrictions on guilty authors' future submissions. In written comments, 15\% to $30 \%$ of both groups emphasised that it was justified to publish overlapping articles when there were different or non-English-speaking audiences, new data, strengthened methods, or disputed findings.

Conclusions: Editors, authors, and other academic leaders should together develop explicit guidelines that clarify points of contention and ambiguity regarding overlapping manuscripts.
E 1981 the International Committee of Medical Journal Editors began to define duplicate publication in its Uniform Requirements for Manuscripts Submitted to Biomedical Journals. ${ }^{1}$ The expanded Requirements for Manuscripts Submitted to Biomedical Journals are now endorsed by over 500 medical journals. The group currently defines "redundant or duplicate publication" as "the publication of a paper that overlaps substantially with one already published", cautioning authors that, if undisclosed, the practice will prompt editorial action. ${ }^{2}$ The National Library of Medicine indexes published notices of cases under the medical subject heading (MeSH) "duplicate publication".

There are numerous problems with redundant publications that are not disclosed to editors or readers (hereafter simply referred to as "redundant articles"). They may break international copyright laws. ${ }^{2}{ }^{3}$ They squander the efforts of journals, editors, peer reviewers, and readers. They inflate authors' curricula vitae, potentially distorting the academic promotions process. ${ }^{4}$ Most importantly, they may mislead the reader about the strength and direction of research findings. For example, they can lead to duplicate counting of subjects in meta-analyses, because subjects from the same trials are reanalyzed repeatedly, without disclosure, in different papers-twice, thrice, or even more-thus biasing the evidence upon which patient care is founded. ${ }^{6-9}$

Studies have shown that the practice of redundant publication is widespread, and may even be increasing. ${ }^{10}$ Editorials and published notices of redundant publication highlight an ongoing problem in diverse journaals. ${ }^{11-17}$ Estimates of incidence within given fields range from $12 \%$ to $28 \%,{ }^{10}{ }^{18}{ }^{19}$ exposing what seems to be a blatant disregard for professional and medical ethics.
A profession has a duty to establish standards, regulate members according to these, and punish those who violate them. ${ }^{20}$ In its definition of redundant publication, the Uniform Requirements proposes such a standard. Yet evidence suggests that authors may not know about, may not understand, or may ignore, such editorial policies. ${ }^{21-23}$ Authors and editors also continue to express confusion about where to draw the line between unjustified and acceptable redundancy. ${ }^{4}{ }^{19} 24-27$ Similarly, while members of the research community appear willing to assign punishments for unethical behaviour, they disagree about what constitutes a suitable response. ${ }^{28}$ Finally, many have emphasised the importance of correcting the scientific literature when cases of misconduct are exposed, but they have also raised questions about who among authors, journals, institutions, federal agencies, or others is responsible for doing so. ${ }^{29}$ We know little, therefore, about why redundant publications occur, what practices might prevent them, and what responses or punishments are appropriate.

The current study assesses the perspectives and practices of editors and authors on issues related to redundant publication. Special attention is paid to identifying areas of consensus and contention. Consensus may indicate support for the implementation of uniform standards. Conversely, contention may underscore the need for mediation between divergent perspectives. If not addressed, these may continue to undermine attempts to define, disclose, and eliminate redundant articles. The study objectives were to determine if there is agreement among authors and editors regarding: the extent of redundant articles; why they occur; when overlapping articles are justified, and how journals should prevent and respond to cases of redundant publication. 


\section{METHODS \\ Subjects}

The target sample was editors and authors who publish research on clinical medicine. The actual sample included editors and authors of articles in journals listed in the 1996 Abridged Index Medicus, which references 124 "high impact" biomedical journals. Twenty five of these journals were excluded because they did not publish original clinical research. In the summer of 1997, we mailed the survey to the senior editor and one randomly selected author from the remaining 99 journals. The selection of the author involved identification of all original research articles (excluding case studies) in the December 1996 issue of each journal, random selection of one of these articles, and identification of the person listed as its corresponding author.

The study was approved by the Committee on Human Research of the University of California, San Francisco (approval \#H2758-13960-01). All participants gave their informed consent to take part and returned the completed survey anonymously.

\section{Survey}

The survey was pretested and modified in response to comments from 25 academicians, both editors and authors. In the study, respondents were asked to use the following definition of a redundant article: "a second article that is based on the same research as the first article, contains no substantially new work or message, and is directed at a similar audience in a similar journal. In addition, the overlap has not been disclosed to the editor or reader" (emphasis in original). "Overlapping article" indicated an article that may or may not have been deemed redundant. The survey was divided into six sections (described below) containing forced choice or open ended questions, with the option of answering "don't know" to any question. In analyses, we defined "consensus" as an agreement of response of $67 \%$ or greater within a group of editors or authors.

Exposure to definitions of redundant publication: Editors were asked if their journal published its definition of redundant publication for prospective authors. Authors were asked if they had ever read the Uniform Requirements' definition of redundant publication.

Extent of redundancy: Editors were asked to estimate, for an average year, the rate of redundant manuscripts they received, as well as the rate of redundant articles published.
We were concerned that authors would not want to admit that a paper of theirs had been labelled as redundant. Therefore, authors received a more inclusive question regarding their knowledge of cases within their immediate sphere of colleagues. They were asked whether "they or a colleague" had ever had a manuscript or publication determined to be redundant by the editor.

Why redundant publications occur: Both editors and authors rated the extent of their agreement with ten proposed reasons for the occurrence of redundant publications-for example, that "authors feel pressure to amass publications". They answered the forced choice questions using the scale $1=$ "strongly disagree", 2 = "disagree", 3 = "agree", and $4=$ "strongly agree"

Whether overlapping papers are ever justified: Respondents indicated whether they believed it to be justified to publish any of sixteen different pairs of overlapping papers. An example of a pair of articles was "a letter to the editor and a research article with the same outcome data". Respondents used the scale 1 = "never justified", 2 = "rarely justified", 3 = "often justified", and 4 = "always justified".

Prevention and response: Regarding redundant articles, editors and authors stated whether they supported potential methods of prevention and response by answering "yes" or "no," for instance, to the proposal that journals "should publish a notice of redundant publication for readers".

Written comments: Respondents were asked to answer two openended questions: "When do you think authors might be justified in publishing research articles that overlap with their previously published work?", and "Do you have any further comments related to the publication of overlapping material?" In addition, spaces were provided in which to write comments following each group of forced choice questions.

\section{RESULTS}

Surveys were completed by $72 \%$ (71/99) of editors and $65 \%$ (64/99) of authors. All but one of these respondents made a written comment on the survey. We also requested demographic information from non-respondents, and received replies from $39 \%(11 / 28)$ of editors and $26 \%(9 / 35)$ of authors (see table 1). The vast majority of all of those contacted were academicians with multiple roles in research, clinical care, and teaching. The most common reason given by non-respondents for not completing the survey was "no time", stated by all authors (9/9) and the majority of editors (7/13).

\begin{tabular}{|c|c|c|c|c|}
\hline \multirow[b]{2}{*}{ Demographic category } & \multicolumn{2}{|l|}{ Editors } & \multicolumn{2}{|l|}{ Authors } \\
\hline & $\begin{array}{l}\text { Respondents } \\
(\mathrm{N}=71)\end{array}$ & $\begin{array}{l}\text { Non-respondents } \\
(\mathrm{N}=111)\end{array}$ & $\begin{array}{l}\text { Respondents } \\
(\mathrm{N}=64)\end{array}$ & $\begin{array}{l}\text { Non-respondents } \\
(\mathrm{N}=9)\end{array}$ \\
\hline \multicolumn{5}{|l|}{ Age } \\
\hline \multicolumn{5}{|l|}{ Gender } \\
\hline Male & $89 \%$ & $63 \% *$ & $84 \%$ & $75 \% *$ \\
\hline \multicolumn{5}{|l|}{ Nationality $\dagger$} \\
\hline English-speaking nation & $100 \%$ & $100 \%$ & $72 \%$ & $78 \%$ \\
\hline USA & $84 \%$ & $86 \%$ & $52 \%$ & $78 \%$ \\
\hline \multicolumn{5}{|l|}{ Primary work activities $\ddagger$} \\
\hline Research & $59 \%$ & $63 \% *$ & $94 \%$ & $88 \% *$ \\
\hline Clinical care & $53 \%$ & $25 \% *$ & $73 \%$ & $75 \% *$ \\
\hline Teaching & $70 \%$ & $63 \% *$ & $70 \%$ & $63 \% *$ \\
\hline \multicolumn{5}{|c|}{ Personal publications, last 5 years } \\
\hline Median number & $23 *$ & 9* & 20 & $15^{*}$ \\
\hline
\end{tabular}

*At least $10 \%$ of respondents did not answer the question.

$\dagger$ Nationality was based on the country listed as the mailing address of the author or editor. English-speaking nations in our sample included Australia, Canada, Great Britain, Ireland, New Zealand, and USA.

$\ddagger$ Respondents were asked to select all categories that applied. 
Table 2 Why redundant publications occur

\begin{tabular}{|c|c|c|c|}
\hline \multirow[b]{2}{*}{ Reason } & & \multicolumn{2}{|c|}{ Percentage who agree } \\
\hline & & Editors $(\mathrm{N}=71)$ & Authors $(\mathrm{N}=64)$ \\
\hline \multirow[t]{4}{*}{ Journals: } & do not do enough to publicise, criticise, and punish cases & $68 *$ & 72 \\
\hline & do not do enough to identify cases during peer review & 49 & 66 \\
\hline & do not publish a clear definition & 34 & 42 \\
\hline & do not think the issue is serious & 6 & 13 \\
\hline \multirow[t]{4}{*}{ Authors: } & feel pressure to amass publications & 75 & 94 \\
\hline & $\begin{array}{l}\text { do not understand how cases distort the aggregation of data (for example, in } \\
\text { systematic reviews or meta-analyses) }\end{array}$ & 58 & 70 \\
\hline & want to disseminate their research as widely as possible & 54 & 69 \\
\hline & do not think the issue is serious & 51 & 53 \\
\hline \multirow[t]{2}{*}{ Academic leaders: } & do not publicly condemn the practice & 48 & 69 \\
\hline & do not think the issue is serious & 25 & $38 *$ \\
\hline
\end{tabular}

Exposure to definitions of redundant publication: Editors reported that only $45 \%$ of their journals publish a definition of redundant publication, and authors that only $50 \%$ of them have read the Uniform Requirements definition.

Extent of redundancy: Editors estimated that a median of 1 in 250 manuscripts (range 0 to $1 / 13$ ) and 1 in 810 published articles (range 0 to $1 / 40$ ) are redundant. The majority of editors answering the question reported having had at least one case of a redundant manuscript $(94 \%, 62 / 66)$ or published article $(72 \%, 47 / 65)$. In reporting on their exposure to cases, $8 \%(5 / 64)$ of authors knew personally of a manuscript and $3 \%(2 / 64)$ of a published paper-either theirs or a colleague's-that had been labelled as redundant.

Why redundant publications occur: Editors and authors were in consensus that redundant publications occur because authors feel pressure to publish (see table 2). While both strongly agreed that journals think the issue is a serious one, they also reached consensus that journals do not do enough to publicise, criticise, and punish cases. There was further consensus among authors, but not editors, that redundant publications occur because academic leaders do not publicly condemn the practice, because authors do not understand how redundant reporting distorts the aggregation of data- for example, meta-analyses-and because authors want to disseminate their research as widely as possible.

In written comments (summary data available upon request), $9 \%$ of authors went on to emphasise their disillusionment with academic leaders and editors. Examples included: "I am fed up with seeing some authors get away with redundant manuscripts! These same authors get away with it consistently and are on editorial boards", and "I notified a senior editor of a fully redundant article that had been submitted to me for review-but he published it anyway".

Whether overlapping papers are ever justified: Editors and authors agreed that most instances of overlapping articles are not justified (see table 3). Out of the entire survey, however, editors and authors disagreed most strongly about overlap between a journal article and an article in a non-peer reviewed symposia supplement. Sixty seven per cent of authors were in consensus that this practice is acceptable, whereas $69 \%$ of editors disagreed. Authors also reached consensus or near consensus that other forms of overlap are justified, specifically: two segmented ("salami sliced") articles, a letter to the editor and a research article with the same outcome data, and two articles with outcome data that overlap by $10 \%$. For both editors and authors, there was a trend

Table 3 Whether overlapping papers are ever justified

\begin{tabular}{|c|c|c|}
\hline \multirow[b]{2}{*}{ Question } & \multicolumn{2}{|c|}{$\begin{array}{l}\text { Percentage who think both } \\
\text { articles are justified }\end{array}$} \\
\hline & $\begin{array}{l}\text { Editors } \\
(N=71)\end{array}$ & $\begin{array}{l}\text { Authors } \\
(\mathrm{N}=64)\end{array}$ \\
\hline \multicolumn{3}{|l|}{ Is it justified to publish two similar articles if the second article is published in: } \\
\hline the internet, in a limited access area & $31^{*}$ & $53^{*}$ \\
\hline the internet, in a public access area & $17 *$ & $44^{*}$ \\
\hline a non-English language journal & 30 & 34 \\
\hline a journal for a substantially different audience & 15 & 19 \\
\hline \multicolumn{3}{|l|}{ Is it justified to publish two articles that have or are: } \\
\hline identical text & 0 & 0 \\
\hline exact duplication of important findings & 0 & 3 \\
\hline exact duplication of background information & 14 & 31 \\
\hline segmented ("salami sliced") articles & 30 & 66 \\
\hline $\begin{array}{l}\text { a letter to the editor and research article with the same outcome data } \\
\text { important findings that are similar and outcome data that overlap by }\end{array}$ & 45 & 66 \\
\hline ... $10 \%$ & 39 & 66 \\
\hline$\ldots 50 \%$ & 4 & 25 \\
\hline$\ldots 100 \%$ & 1 & 5 \\
\hline \multicolumn{3}{|l|}{ important findings that are different and outcome data that overlap by ... } \\
\hline$\ldots 10 \%$ & 51 & 69 \\
\hline$\ldots 50 \%$ & 32 & 53 \\
\hline$\ldots 100 \%$ & 23 & 30 \\
\hline
\end{tabular}


Table 4 Prevention and response

\begin{tabular}{|c|c|c|}
\hline \multirow[b]{2}{*}{ Strategy } & \multicolumn{2}{|c|}{$\begin{array}{l}\text { Percentage who } \\
\text { support strategy }\end{array}$} \\
\hline & $\begin{array}{l}\text { Editors } \\
(\mathrm{N}=71)\end{array}$ & $\begin{array}{l}\text { Authors } \\
(\mathrm{N}=64)\end{array}$ \\
\hline \multicolumn{3}{|l|}{ Prevention by identifying overlapping manuscripts during peer review } \\
\hline request that peer reviewers notify editors about potential overlap & 99 & 94 \\
\hline require that authors sign statements denying or disclosing overlap & 93 & 94 \\
\hline request that authors submit articles that potentially overlap & 89 & 77 \\
\hline arrange with other journals to impose sanctions on authors of redundant articles & $62 *$ & $64 *$ \\
\hline perform bibliographic searches for overlapping articles & $34 \dagger$ & $59^{*}$ \\
\hline \multicolumn{3}{|l|}{ Response to redundant publications } \\
\hline notify authors & 100 & 98 \\
\hline notify other journal & 93 & 80 \\
\hline publish a notice of redundant publication for readers & $79 *$ & 66 \\
\hline impose restrictions on author's future submissions & $68 \dagger$ & $39 \dagger$ \\
\hline inform institution where author works & $66 \dagger$ & $42 *$ \\
\hline inform indexing services & $62 \dagger$ & $52^{*}$ \\
\hline inform funding source of the research & $42 \dagger$ & $33^{*}$ \\
\hline
\end{tabular}

suggesting that the publication of two overlapping articles with different conclusions is more justified than that of two with the same conclusions. Both groups also believed that dual publication becomes less justified as the overlap in data increases. Finally, questions regarding publication on the internet received the most ambiguous responses, with at least $10 \%$ of editors and authors answering "don't know".

In written comments, $16 \%(11 / 71)$ of editors and $14 \%$ $(9 / 64)$ authors stated that overlapping papers are rarely or never justified (in $8 \%(20 / 250)$ of all comments made by both groups). Fifty two per cent (131/250) of all comments, however,described cases of acceptable overlap. Fifteen per cent to $30 \%$ of both editors and authors felt that overlapping publications are justified when there is new information, the research methods are strengthened, or the research findings are in dispute. Furthermore, some of the most forceful comments opposed points of aggregate consensus in the forced choice questions: $16 \%(23 / 141)$ of comments by editors and $13 \%$ (14/109) of comments by authors supported overlapping or redundant publications when the audience is different or non-English speaking. For example, one author wrote: "Non-American authors must often publish in two languages. American 'peers' do not understand. There is a cultural fight!"

Prevention: There was consensus among editors and authors on a number of points of prevention (see table 4): that authors should sign statements for journals attesting that their manuscript does not overlap substantially with other of their articles (unless disclosed); that authors should submit with their manuscript copies of any overlapping articles, and that editors should ask peer reviewers to notify them about manuscripts that overlap with previously published work. On this latter item, only $17 \%(10 / 60)$ of authors who are also peer reviewers described ever having received a journal request that they notify the editor about potentially redundant manuscripts. Instead, $47 \%$ of these peer reviewers said they had notified editors on their own initiative. In their role as journal readers, 17\% (11/64) of all authors reported having written a letter to the editor stating that a published article was redundant.

In written comments, a high proportion of all editors (28\%) and authors (16\%) emphasised that disclosure of previous work is essential to prevention. An editor summarised: "The key is whether the overlap is declared at the outset. Failure to declare the possibility of redundant publication is prima facie evidence [of guilt]." Another explained that journals need to standardise how they attempt to prevent cases: "This is a serious problem, but one that is currently not approached in a uniform manner by journals or editors". While generally sup- portive of prevention strategies, however, $14 \%$ of editors were adamant that one such strategy, that of bibliographic searches, would be "much too labor intensive and costly" to implement.

Response to cases: Both editors and authors reached consensus or near consensus that journals should respond to redundant publications by notifying the authors, the journal that published the other article, and the reader (see table 4). However, only $67 \%$ (33/49) of editors who have had cases and answered the question report consistently publishing notices of redundant publication for readers. Furthermore, only 55\% of these notices (18/33) are listed in the table of contents, which is the only consistent means ofeinsuring that they get indexed on Medline. The clearest difference of opinion between editors and authors regarded strict sanctions: there was consensus or near consensus among editors that journals should restrict future submissions from authors of papers deemed redundant, as well as inform their institutions-but most authors disagreed. On many topics of response, as well as prevention, at least $10 \%$ of both editors and authors answered "don't know" to the question.

In written comments, $16 \%(11 / 71)$ of editors and $14 \%$ (9/64) of authors supported the role of journals and academic institutions in regulating and imposing sanctions on authors. They stressed, however, the need for careful deliberation-for example, "due process and "case by case decision making". One author cautioned: "We have to be careful about journal editors becoming judge, jury, and executioner".

\section{DISCUSSION}

There were many points of consensus between editors and authors. Both groups agreed that redundant publications occur because authors feel the pressure to publish and journals do not do enough to publicise, criticise, and punish cases. Both also felt that journals can help prevent cases by requiring that authors sign statements denying or disclosing overlap; that authors submit other papers that overlap, and that editors ask peer reviewers to notify them about manuscripts that overlap with previously published work. Editors and authors agreed as well that journals should respond to redundant publications by notifying the authors, the other journal, and readers. Finally, on forced choice questions, both groups opposed publication of most forms of overlapping articles. There were also, however, points of contention and ambiguity. Many more authors than editors believed that it is justified to publish certain types of overlapping articlesnamely, a second article published in a non-peer reviewed symposia supplement or as a letter to the editor, two 
segmented articles, or two articles that overlap in $10 \%$ of their outcome data. Written comments stressed many other exceptions: when there is a different or non-English speaking audience, new data, strengthened methods, or disputed findings. In response to a redundant publication, editors but not authors supported imposing restrictions on the author's future submissions. Finally, editors and authors were equivocal regarding overlapping publication on the internet and a number of methods of prevention and response.

\section{Findings placed in the context of previous work}

The median estimate by editors of the rate of redundant publication ( 1 in 810) is far below the rates reported within specialty journals ( 1 in $4-10)^{10} 1819$ or by meta-analysts. ${ }^{6-9}$ Possible reasons for this discrepancy are that the editors in our survey used a more stringent definition of redundancy in their calculations, recalled only the most egregious cases, or did not have the time or expertise to identify duplicates within their journals.

While most journals prohibit redundant publication, ${ }^{30}$ only $45 \%$ of editors in our study reported that they publish a definition to guide authors. Our finding that only $50 \%$ of authors have read the definition of redundant publication in the Uniform Requirements is similar to other findings regarding awareness and fulfillment of the Requirements' authorship criteria. ${ }^{21-23}$

It is perhaps not surprising that our respondents strongly believed that the pressure to publish contributes to redundant publication. Other studies describe how trainees and applicants for faculty positions have padded their resumes by claiming authorship on publications that were unverifiable or that did not list them as authors. ${ }^{31-35}$ Some funding agencies allocate financial support for an institution largely on the basis of its scientific publications. ${ }^{36}$ Academic leaders may not be doing enough to counteract such incentives to inflated curricula vitae, as $69 \%$ of our author respondents blamed them for not publicly condemning redundant publications.

Seventy per cent of authors and $58 \%$ of editors also felt that redundant publications occur because authors do not understand how these distort the aggregation of data, as in meta-analyses. Again this is not unexpected, given the considerable evidence in the literature that duplicate publications go unrecognised. Gotzsche reported that 31 trials comparing non-steroidal, anti-inflammatory drugs had generated 75 articles, with the majority of duplicates published in English and within one year of each other, but without any subsequent notice of duplicate publication. ${ }^{6}$ Huston and Moher attempted to disentangle the source data of articles on the antipsychotic risperidone and ultimately concluded that data from a single North American multicentre trial had generated six articles but that the publication record was too confusing to determine how many articles had resulted from a similar European trial. ${ }^{7}$ Tramer et al described nine trials on the efficacy of the anti-emetic ondansetron had spawned 23 articles, without cross referencing, and that others had innocently cited the duplicate data alongside the original data in no less than four research articles, two review articles, a textbook, and a review article on the ethics of anti-emetic trials. ${ }^{8}$ While conducting a meta-analysis of antifungal agents, Johansen and Gotzsche found that one (and perhaps another) of 12 articles was a duplicate. ${ }^{9}$

If such double counting goes unrecognised, readers may be misled as to the strength, or even direction, of the evidence. Gotzsche found that of articles published on the same data, the later duplicates were more likely to contain favourable conclusions and side effect profiles. ${ }^{6}$ Similarly, Tramer et al concluded that a failure to exclude duplicates from their meta-analysis would have overestimated the treatment efficacy by $23 \% .{ }^{8}$ Upon being contacted, authors of the original report, the duplicate report, or both, confirmed the duplication of five of the nine trials, suggesting that they felt little reticence about admitting to the overlap. This attitude may be partially explained by our findings that authors, much more than editors, support publication of some forms of overlapping papers.

Finally, authors and editors agreed that journals should do more to publicise and punish cases. Over $67 \%$ of editors supported imposing restrictions on the future submissions of authors of redundant publications, which corresponds to the practices of a number of journals, ${ }^{37-39}$ some of whom who have formed joint agreements to this effect. ${ }^{40-43}$ Respectively, $79 \%$ and $66 \%$ of editors and authors in our study supported publishing a notice of redundant publication, just as others have found that $55 \%$ of academicians support printing a journal retraction in a similar scenario. ${ }^{28}$

\section{LIMITATIONS}

Non-respondents may differ in demographics, opinions, and practices from those who completed the survey, limiting the generalisability of our findings. Recall or self report bias may have influenced the description of actual cases. Our findings also may not be generalisable to authors and editors of journals not included in the Index Medicus.

\section{IMPLICATIONS}

According to our study finding, editors and authors agree that most forms of redundant publication are unacceptable, even while they identify the motivations for their occurrence. They also concur on some means of prevention and response. Such points of consensus can help form the foundation for uniform policies on redundant publication. There are, however, areas in which differences of opinion leave room for continuing controversy. More authors than editors believe it is justified to publish certain types of overlapping articles, and they may have legitimate reasons for these beliefs. The important question is whether the overlap will be disclosed or whether duplicate data will continue to bias the literature. Given such stakes, and the areas of disagreement and ambiguity in our study, it would be prudent for editors, authors, and academic leaders to mediate their differences.

\section{POLICY RECOMMENDATIONS}

The time has come for editors, authors, and academic leaders to jointly clarify and enforce mutually acceptable standards on redundant publication. Journals should publish an explicit definition and notices of cases; require authors to deny or disclose overlap, and submit overlapping work for review, and involve peer reviewers in attempts to identify redundant work. If authors fail to disclose, based on our study sample, journals have the mandate to correct the record by exposing their redundant publication. Authors themselves should read and abide by published definitions of redundant publication and should fully disclose overlap to editors and readers. Finally, academic leaders, and the medical training institutions where they work, have a responsibility to promote ethical practices. ${ }^{20}$ Therefore, academic leaders and centres should examine their own practices, change them if necessary, and then clearly and publicly condemn redundant publications.

\section{AUTHORS' NOTE}

Some data contained in this paper appeared in a poster presentation at the Third International Congress on Peer Review of Biomedical Publication, September 1997, Prague, Czech Republic.

\section{FUNDING}

VY was supported in part by a Dean's Summer Research Fellowship, University of California, San Francisco. 


\section{ACKNOWLEDGMENTS AND CONTRIBUTIONS}

Veronica Yank conceived of and designed the study, designed and coordinated the survey, managed the data, analysed the data, wrote and revised the paper, and guarantees the integrity of the study. Deborah Barnes conceived of and designed the study, helped to revise the survey, analyse the data, and edit the paper, and guarantees the integrity of the study. Lisa Bero and Drummond Rennie gave feedback on the study design, survey, and paper.

\section{Authors' affiliations}

V Yank, The Institute for Health Policy Studies and Medical School, University of California, San Francisco, California, USA

D Barnes, The Division of Geriatrics, Department of Medicine, University of California, San Francisco, California, USA

\section{REFERENCES}

1 International Committee of Medical Journal Editors. Uniform requirements for manuscripts submitted to biomedical journals. BM 1982;284:1766-70

2 International Committee of Medical Journal Editors. Uniform requirements on manuscripts submitted to biomedical journals [online publication]. Updated Oct 2001. Accessed 6 Feb 2002. Available from: URL: http://www.icmje.org/index.html\#top

3 Hanke CW, Arndt KA, Dobson RL, Dzubow et al. Dual publication and manipulation of the editorial process. International Journal of Dermatology 1990;29:71 1-12

4 Angell M, Relman AS. Redundant publication. N Engl J Med 1989;320:1212-14.

5 Rennie D. Fair conduct and fair reporting of clinical trials. JAMA 1999;282:1766-8

6 Gotzsche P. Multiple publication of reports of drug trials. Eur J Clin Pharmacol 1989;36:429-32.

7 Huston P, Moher D. Redundancy, disaggregation, and the integrity of medical research. Lancet 1996;347:1024-6

8 Tramer MR, Reynolds DJM, Moore RA, McQuay et al. Impact of covert duplicate publication on meta-analysis: a case study. BM 1997; 315:635-40.

9 Johansen $\mathbf{H}$, Gotzsche P. Problems in the design and reporting of trials of antifungal agents encountered during meta-analysis. JAMA 1999;282:1752-9.

10 Waldron T. Is duplicate publishing increasing? BM 1992;304:1029

11 Chou S. Duplicate publication: author's apology. Science 1997;277:17.

12 Anon. Notice: overlapping publication. Ann Intern Med 1998;1 28:698.

13 Anon. Notice of inadvertent duplicate publication. BM 1999;318:157.

14 Anon. Notice of duplicate publication. Thorax 2002;57:6.

15 Anon. Correction: notice of duplicate publication. Radiology 2001;219:300.

16 Anon. Double publication in Human Reproduction volume 15, supplement 1, 2000. Hum Reprod 2001;16:1542.

17 Anon. Notice of duplicate publication. Pediatr Allergy Immunol $2001 ; 12: 53$

18 Blancett S, Flanagin A, Young R. Duplicate publication in the nursing literature. Image J Nurs Sch 1995;27:51-6.
19 Cameron I, Beard J, Reed M. Duplication of surgical research presentations. BM 1997;314:346-7.

20 Gunsalus CK. Ethics: sending out the message. Science 1997;276:335

21 Goodman N. Survey of fulfilment of criteria for authorship in published medical research. BN 1994;309:1482.

22 Bhopal R, Rankin J, McColl E, et al. The vexed question of authorship: views of researchers in a British medical faculty. BMV 1997;314:100912

23 Yank V, Rennie D. Disclosure of researcher contributions: a study of original research articles in The Lancet. Ann Intern Med 1999;130:661-70.

24 Federman D, Mutgi A. Redundant publication? N Engl J Med 1992:327:1316.

25 Lau J, Antman E, Chalmers T. Redundant publication?: the authors reply. N Engl J Med 1992;327:1316.

26 Kassirer J. Redundant publication?: editor's reply. N Engl J Med 1992;327:1316.

27 Earnshaw JJ, Farndon JR, Guillou PJ, et al. Dual publication of surgical abstracts is acceptable. BM 1997;314:1903-4.

28 Wenger NS, Korenman SG, Berk R, et al. Punishment for unethical behavior in the conduct of research. Acad Med 1998;73:1 187-94.

29 Parrish DM. Scientific misconduct and correcting the scientific literature. Acad Med 1999;74:221-30.

30 Asai T, Shingu K. Ethical considerations in anaesthesia journals. Anaesthesia 1999;54:172-97.

31 Sekas G, Hutson WR. Misrepresentation of academic accomplishments by applicants for gastroenterology fellowships. Ann Intern Med 1995;123:38-41.

32 Gurudevan SV, Mower WR. Misrepresentation of research publications among emergency medicine residency applicants. Ann Emerg Med 1996;27:327-30.

33 Panicek DM, Schwartz LH, Dershaw DD, et al. Misrepresentation of publications by applicants for radiology fellowships: is it a problem? Am J Roentgenol 1998;170:577-81.

34 Aykut B, Shugerman RP, Robertson WO. Misrepresentation of authorship by applicants to pediatrics training programs. Acad Med 1998:73:532-3.

35 Goe LC, Herrera AM, Mower WR. Misrepresentation of research citation among medical school faculty applicants. Acad Med 1998;73:1 183-6.

36 Sheikh A. Publication ethics and the research assessment exercise: reflections on the troubled question of authorship. J Med Ethics 2000;26:422-6.

37 Berk P. Redundant publication: deja vu all over again. Hepatology 1992;16:840-2.

38 Susser M, Yankauer A. Prior, duplicate, repetitive, fragmented, and redundant publication and editorial decisions. Am J Public Health 1993;83:792-3.

39 Doherty M. The misconduct of redundant publication. Ann Rheum Dis 1996;55:783-5.

40 Bier DM, Fulginiti VA, Garfunkel JM, Lucey et al. Duplicate publication and related problems. Am J Dis Child 1990;144:1293-4.

41 HEART Group. HEART Group notification regarding redundant publication. Chest 1997:112:254-5

42 Edwards G, Holder S, Wist R, et al.Addiction journals: amazing happenings, landmark meeting, historic consensus, evolving process. Addiction 1997;92:1613-16.

43 Anon. Consensus statement on submission and publication of manuscripts. Surgery 2001;129:662-3. 